\title{
Database Creation and Floodplain Mapping of a Residential Layout in Yola, Nigeria
}

\author{
Ibrahim Muhammed, Ezra Enoch Alhamdu, Mukailu Mohammed \\ Department of Surveying \& Geoinformatics, School of Environmental Sciences, \\ Modibbo Adama University of Technology, Yola, Nigeria
}

\begin{abstract}
Topographic mapping of flood-prone housing estate has been studied using high resolution $3 D$ data from total station. The total station provides an unprecedented accuracy for a 3D data collection than any other traditional surveying techniques and the satellite-based differential GPS. The Digital Terrain Model (DTM) delineates the potential areas required for drainage construction. It is observed that over $80 \%$ of housing facilities could be saved from flood water if proper drainages are constructed as indicated by the DTM. Generally, houses to the east and south would be much affected due to their location in low land areas. Supplementary, a spatial database of the housing estate has been conducted to predict loses that may incur during the perennial and climate-forced floods that affect the area. This database can be queried and based on the entity relationships of each house, potential economic loses can be calculated. It is suggested here that additional options, such as flow direction, slope and watershed analyses could be conducted in future flood mapping of the area.
\end{abstract}

Keywords: Flood, Mapping, Database, Total Station, DEM

\section{Introduction}

Topographic maps are indispensable aids to the understanding of the features and terrain of land. It is the most widely used map covering the fields of engineering, planning, industry, utility management, environmental management and defense. In engineering, it is required for route planning, rail construction and estimate the volume of earth work. In planning, it is used for the location of industries, residential, recreational and hazards area location. Industrial needs of this map are at the forefront because it is required to study route to transport goods, direction and ease of bringing in raw materials and market locations. Utility managers use it to plan the distribution of electricity, water and sewage system prior to construction. The defense comprising both the army and air force need topographic map for reconnaissance purposes. This also applies to archeologists, historians and tourists alike.

Topographical maps are also very vital in identifying areas vulnerable to flood and erosion. The advantage of having a 3D coordinate of a terrain and then recording the presence of man-made and natural features make it essential for management of land resources. Generally, for us to be able to comprehend physical features on land, the topographic map becomes an essential tool (Bannister, 2006).

There are various methods used in collecting data for topographical surveys. These include 1) tacheometry, that involves taking distances from optical instruments such as theodolites and levels using leveling instruments, that are aimed at hilly rough terrains. 2) Aerial photography in which 3D maps involving terrain features are mapped. 3) Use of Global Positioning System that involves worldwide navigational and surveying based on the reception of signals from an array of orbital satellites. 4) Total Station, an instrument that incorporate digital theodolite and an Electronic Distance Measurement (EDM) equipment. 5) Mapping using satellite radar, that involves global topography, such as Shuttle Radar Topography Mission (SRTM). Others include Light Detection and Ranging (LiDAR) and Interferrometric Synthetic Aperture Radar (IfSAR).In this study, the Total Station is employed to obtain the 3D coordinates and existing surface features. It is an important that provides data for flood plain mapping.

The practice of modern surveying is undergoing rapid change due to availability of electronically controlled instruments, the widespread adoption of the Global positioning systems (GPS), and the proliferation of various Geographic and Land Information Systems (GIS/LIS) (Moffat and Bossier, 1998; Ayeni, 2006). It is also possible to model topological relationships of various earth surface entities and analysis be performed to predict future changes, and that assist decision makers to facilitate working on spatial environment. Administrative authorities could create a spatial data instruction by which the database may easily be exchanged (Konecny, 2001). The major advantage of GIS is that data can be shared across a wide network of users, redundancy can be controlled and it provides a convenient user interface that will maintain multiple users (Aronof, 1991).

The process of digital mapping using GIS provides the ability to collect, compile and format data into a virtual image (Jonathan, 2009). The primary function of this technology is to produce maps that give accurate 
representations of particular areas and detailing all features of interest that would be valuable to a user. Databases can be used to create other information systems such as police information system (PIS) Environment information system (EIS), Agricultural information system (AIS), Utility information system (UIS) and land information system (LIS) (Ekpete, 2005). Databases are classified according to different criteria depending on the data model structure (Agajelu, 1994). The navigation data structure is hierarchical in nature while that of relational database structure are organized in a series of two dimensional tables with each containing record of entity, linkage between the tables.

Topographic maps usually portray both natural and artificial features. They show and name works of nature inducing mountains, plains, lakes, rivers and Vegetation, they also identify the principal works of man, such as roads, boundaries, transmission lines, and major buildings, the most widely used of all maps is the topographic map. The features that most distinguishes topographic maps is the use of contour line to portray the shape and elevation of the land. Topographical maps render the general terrain configuration showing the Undulating nature of the earth surface (Roy, 1990).

It has been described by Heinz (1997), that the basic type of map use to represent land areas is the topographic map. Such maps show the natural features of the area covered as well as certain features, known as cultural features, political boundaries, such as the limits of towns, states and countries. Elevations on topographic maps are shown chiefly by use of superimposed contours, connecting points of equal evaluation, to give a readable picture of the terrain. The distinctive characteristic of a topographic map is that the shape of the earth's surface is shown by contour lines. A topographic map shows more than contours, the map includes symbols that represent such features, as streets, buildings, streams and vegetation. These symbols are constantly refined to better relate to the features they represent, improve the appearance of readability of the map and reduce production cost. Consequently, within the same series, maps may have slightly different symbols for the same feature Examples of symbols that have changed include built up areas, roads, intermittent drainage, and some lettering styles. The main preoccupation in this context is the creation of a topographic database on to which the thematic data of specific interest may be added.

The risk that a flooding event will be a disaster is a function of three factors, namely: Hazard associated with the flood, the human and natural systems exposed to flood waters, and the vulnerability of these systems to flooding (Jonkman, 2005). The fourth Report of the Intergovernmental Panel on Climate Change (IPCC-4) has brought to the fore the severity and global dimension of the impacts of climate change. With the brunt of the climate change coming to stay, rainfall variability is expected to be on the increase, and places that used to be predominantly safe from floods will also be affected (Diaz, 2006).

The extent to which a flood causes impact rests not only on the magnitude of the flood but also by human and societal choices related to behavior, economy, infrastructure and others (Lowe et al, 2013).

While digital topography mapping is well established in modern mapping particularly for flood prediction, it is also possible to analyse loses that may incur during floods. In this paper, we have developed a topographic map and also the created a database of cost of residential houses in the study area so as to predict the amount of loses that may incur during a flood event.

\section{Study Area}

The study area is sandwiched between two twin towns, Jimeta and Yola. It lies between latitude $\left[9^{\circ} 15^{\prime}\right.$ $20^{\prime \prime}$ and $\left.9^{\circ} 16^{\prime} 05^{\prime \prime} \mathrm{N}\right]$, and longitude $\left[12^{\circ} 26^{\prime} 12^{\prime \prime}\right.$ and $\left.12^{\circ} 27^{\prime} 04^{\prime \prime} \mathrm{E}\right]$ of the Greenwich meridian (figure 1).

The Eighty Housing Units were designed and develop in the early 1980s. This estate was developed without considerations of greater Yola master plan, and due to lack of planning and environmental impact assessment, the estate is continually affected by perennial flooding. This occurs especially during the peak periods of the rainy season in August/September. The area is also affected when River Benue over floods due to the release of excess water from Lagdo Dam in the neighbouring Cameroon Republic. Excess water from Lagdo Dam is released when it cannot contain water due to surplus rain water arising from the changing climate.

The climate of the study area is generally temperate. The average monthly temperature fluctuates between $18^{\circ} \mathrm{c}$ around December and January (coldest months) to $45^{\circ} \mathrm{c}$ around April (hottest month) which is the peak of the maximum temperature. The average annual precipitation in the study area is about $960 \mathrm{~mm}$. There are two distinct seasons; the dry season which commences from the month of November and ends in April and the rainy season starts from May to October with a higher rainfall recorded during the months of August and September when the intensity assumes over $25 \%$ of the annual value. The dry months are January and February with an average humidity of about $28 \%$. The relative humidity starts increasing gradually from April and reaches the peak (80\%) in August and September from it where it starts declining in October to the minimum following the cessation of rains (Source: NIMA, 2004). 


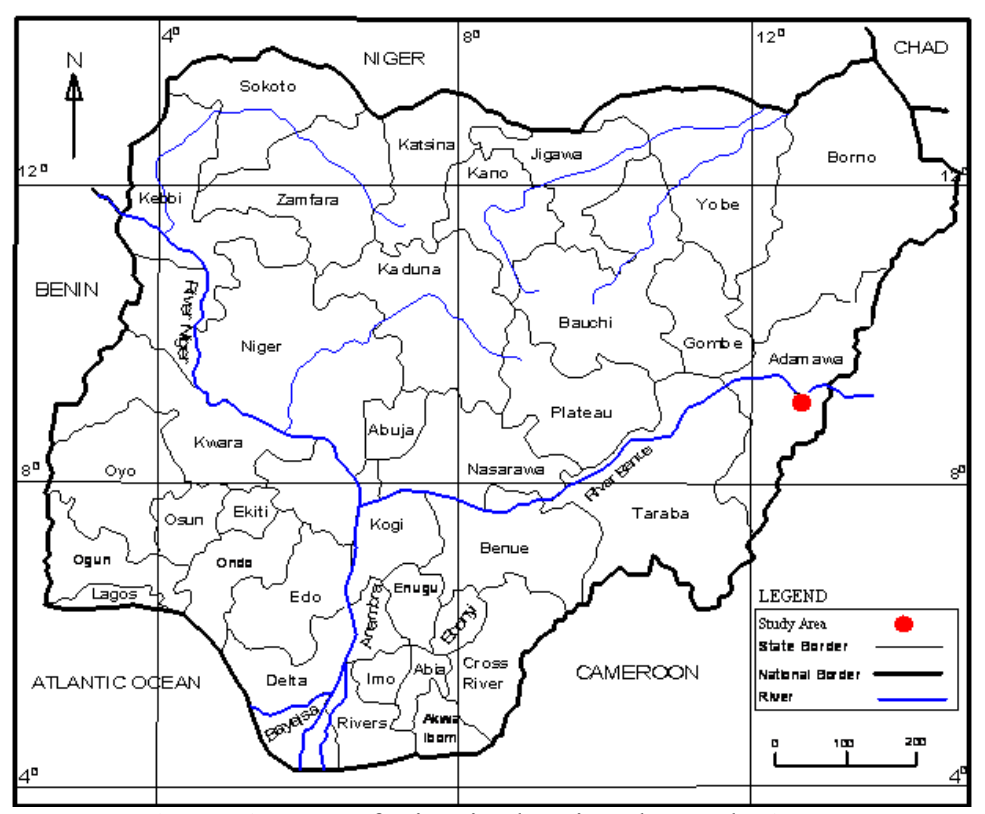

Figure 1: Map of Nigeria showing the study Area.

The relief of the study area is generally low from $152.4 \mathrm{~m}$ to $213.4 \mathrm{~m}$ above mean-sea level. Some parts of Yola-North are located on a fairly plain terrain, like karewa G R A and Karewa Extension, while other parts of the town are undulating rough and rugged terrain. The north eastern part of the Yola north is located on the gentle slope of sedimentary rock escarpment $(213 \mathrm{~m})$, in which the steep side of the escarpment from the bank of River Benue forms the boundary on the north-east, running from south-east down to north-west.

The geology of the study area is the oldest cretaceous sedimentary formations consisting of some alluvial deposition hitch unconformable overlie the cretaceous deposits. The sedimentary deposits within the rift that runs through the central axis Yola aim eastward, separate the political land of Adamawa state into two halves. The structural development of the rift had been associated to wrench-fall tectonic and formation of pullapart basins in which Yola-North is located with the cretaceous continental deposits at the south-east of River Benue. The soil in the study area is classified as ferruginous tropical soil with a marked differentiation of horizons and abundance of free non-oxides usually deposited as red-yellow mottles or concretes (source: NIMA, 2004). This paper is organized as follows: 1) Introduction, 2) Study Area, 3) Materials and Methods, 4) Results and Discussion, 5) Summary and Conclusion.

\section{Materials And Methods}

This research employs the use of Total Station instrument (SOKKIA SET 530R) and its contingents, handheld GPS, compass, ranging poles, $100 \mathrm{~m}$ steel tapes and a computer system. Software packages used are AutoCad 2010 and ArcGIS 9.2.

The method involves collecting $3 \mathrm{D}(\mathrm{x}, \mathrm{y}, \mathrm{z})$ coordinates of spots and building corners that are used to plot contours and Digital Terrain Models (DTM). Before the commencement of observation, the coordinate $\left(\mathrm{E}_{0}\right.$, $\mathrm{N}_{0}, \mathrm{H}_{0}$, ) of reference station, that of instrument station, height of instrument and height of reflector were inputted before turning to obtain the coordinates of points of interest. The flow chart of the research work is shown in figure 2.

As a data acquisition procedure, existing map of the area was used to guide the process. Field observations involved use of the total station to collect 3D data. These data are processed to provide contour map and Digital Terrain Model. Attribute information for each household comprising House Owner, House Number, House Value, No of Bedrooms and Fees Charged by government were collected and then used to create database in combination with the spatial map obtained. This integrated map provides the ability to query information regarding each household. The information that can be queried here are house owner and cost of houses. The final products are the various plots and the database. 


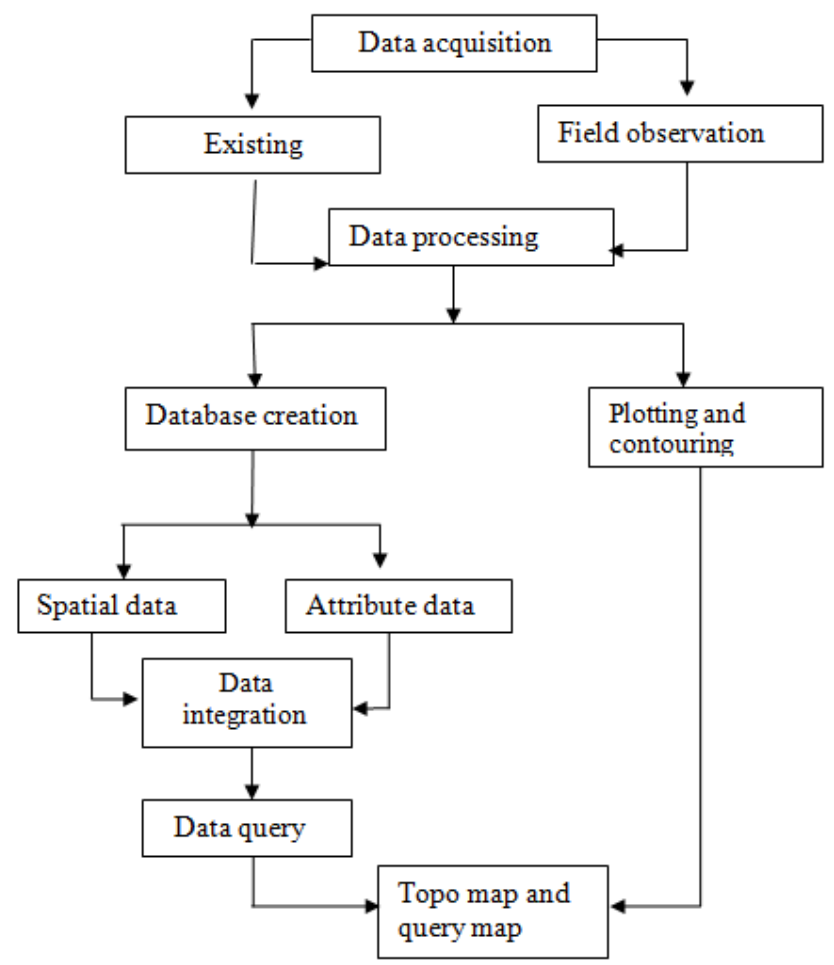

Figure 2: Flow chart of method used.

To establish quality of field work, carefulness by the observer was ensued. The period of observation also matters, because optical instruments tend to expand during hot tropical sun. Observations were therefore made during cold afternoons. In using the total station, usually information are stored and displayed digitally in the electronic field book. Transferring into a software is relatively easy compared to optical instruments.

\section{Results And Discussion}

Detail survey of the eighty housing units was carried out in order to produce a topographic map of the area and also design a database for the housing units. The instruments used to achieve this work were the prismatic compass and total station. The prismatic compass was employed in fixing of details, while the total station was used to acquire the 3D coordinates of the entire study area, including the boundary points.

The data obtained from the field covering the entire area was employed in the production of the contour map (figure 3). The contour map shows lines joining spot heights of equal value. Close to Yola - Jimeta road lies upper ground while to the east is lower ground. By implication, this has given us a view that higher grounds are safer zones during floods. Areas to the east are more likely vulnerable to flood. This could be explained further by the DTM.

The data used for the contouring were subsequently imported into AutoCAD and ArcGIS software packages to produce the digital terrain model (DTM). This is based on terrain modeling, which is the technique that represents the nature of the earth surface as a mathematical expression. In surveying and engineering, it has large number of applications including contouring, high way design, pipelining and earthwork calculation. In addition to contour generation, DTM have numerous applications in engineering survey. They can be viewed from different perspective and presented as a wired frame and triangular mesh surface perspectives views, which can highlight areas of specified interest. Topographic mapping and DTM production are central to this study that focuses on areas liable to flood. This means that investigating the nature of the topography could effectively assist civil engineers and other consultants in the designing drainage channels in the eighty housing units. 


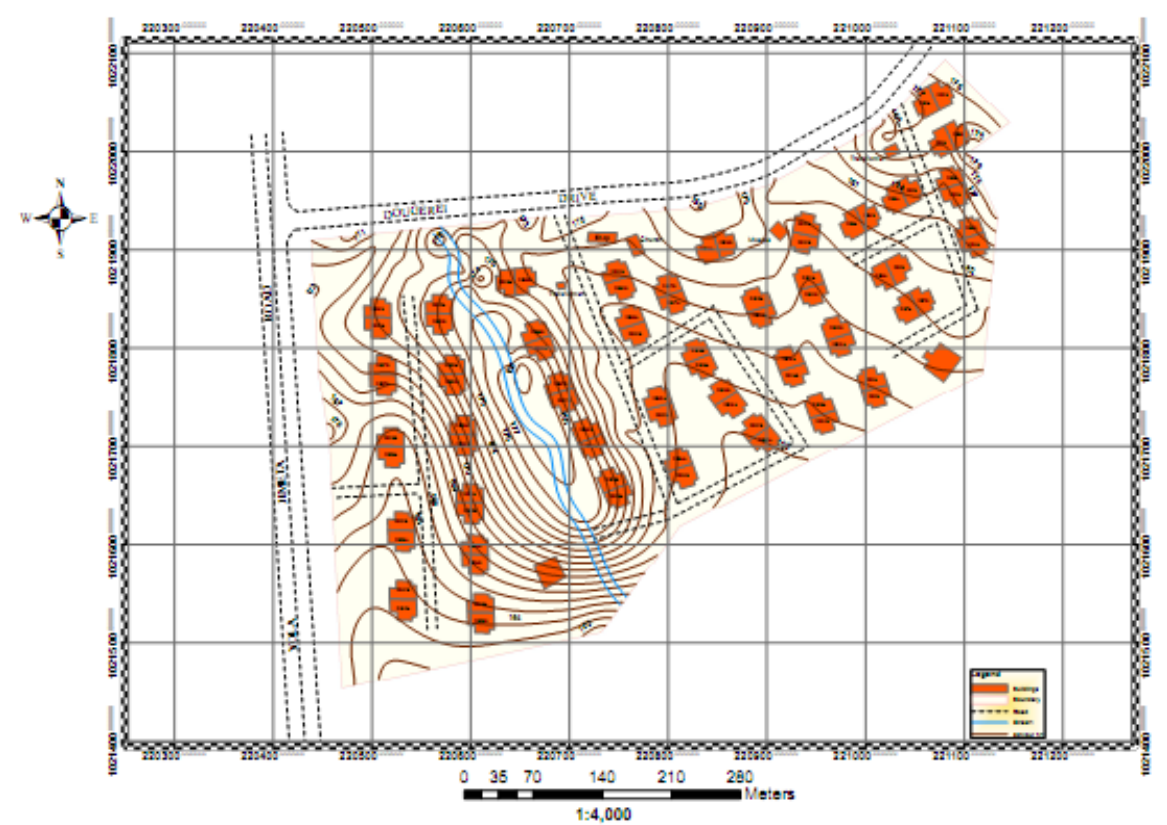

Figure 3: Overlay of buildings on contour lines.

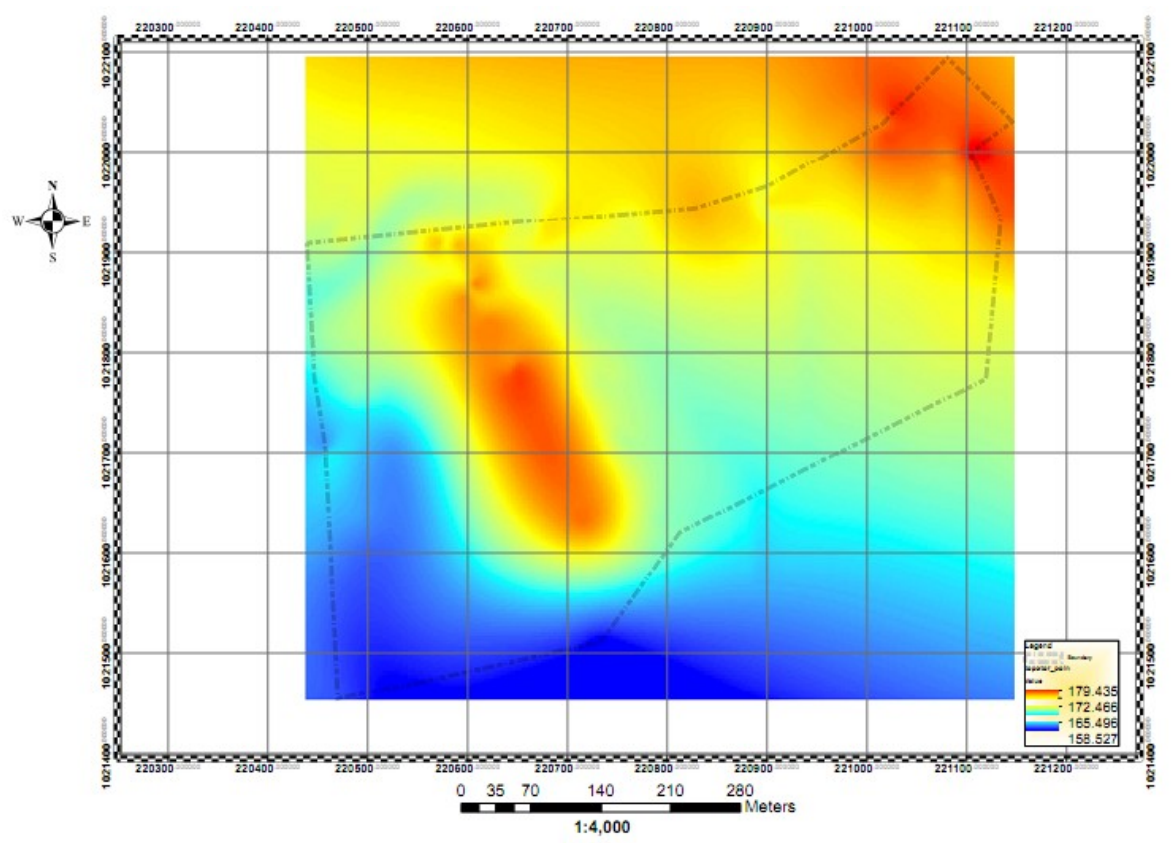

Figure 4: Digital terrain model of the study area.

The DTM (figure 4) show areas of high (in red) and low (in blue) topography. This effectively shows that drainage pattern should be southward, considering upper grounds to the centre and the northeast, and slightly high to the north. From the legend, one could see that difference in elevation between the upper ground to the centre and that of lower ground to the south $(179.435-165.495=13.94 \mathrm{~m})$. The difference in height of about $14 \mathrm{~m}$ indicate steep slope, and this explains the very necessity to have a viable and permanent drainage network to provide access to overflowing water. Of course, this area is affected by both perennial flood due to poor drainage and flooding related to the changing climate. It is hoped that having a proper direction and well constructed drainages the problem would be solved.

When floods occur, damages are expected on both existing structures and properties of inhabitants. It is possible to analyze risks associated with flood in these areas. Analysis of risks goes together with costing. Therefore, we create a database of costs of each house in the area to assess how much can be lost in case flood damage occur. This database shows both attribute and spatial information regarding the houses. Here, we are 
only interested in the house value, as this will enable us determine the amount of lost that can be incurred during a flood disaster. We have not considered items belonging to houses because these are unquantifiable.

Basically the entity relationship approach was used in the design of the database for cadastral land parcel. Here the entity relationship requires that the various entities must have been determined before the commencement of the design. The attribute table for the eighty housing units was also designed. It is important to note that all the houses are for residential purposes.

The query map (figure 5) shows a panel to the left, indicating attribute information about the houses. House value of $\$ 1,350,000.00$ was chosen and these are indicated by light blue colours over the buildings queried.

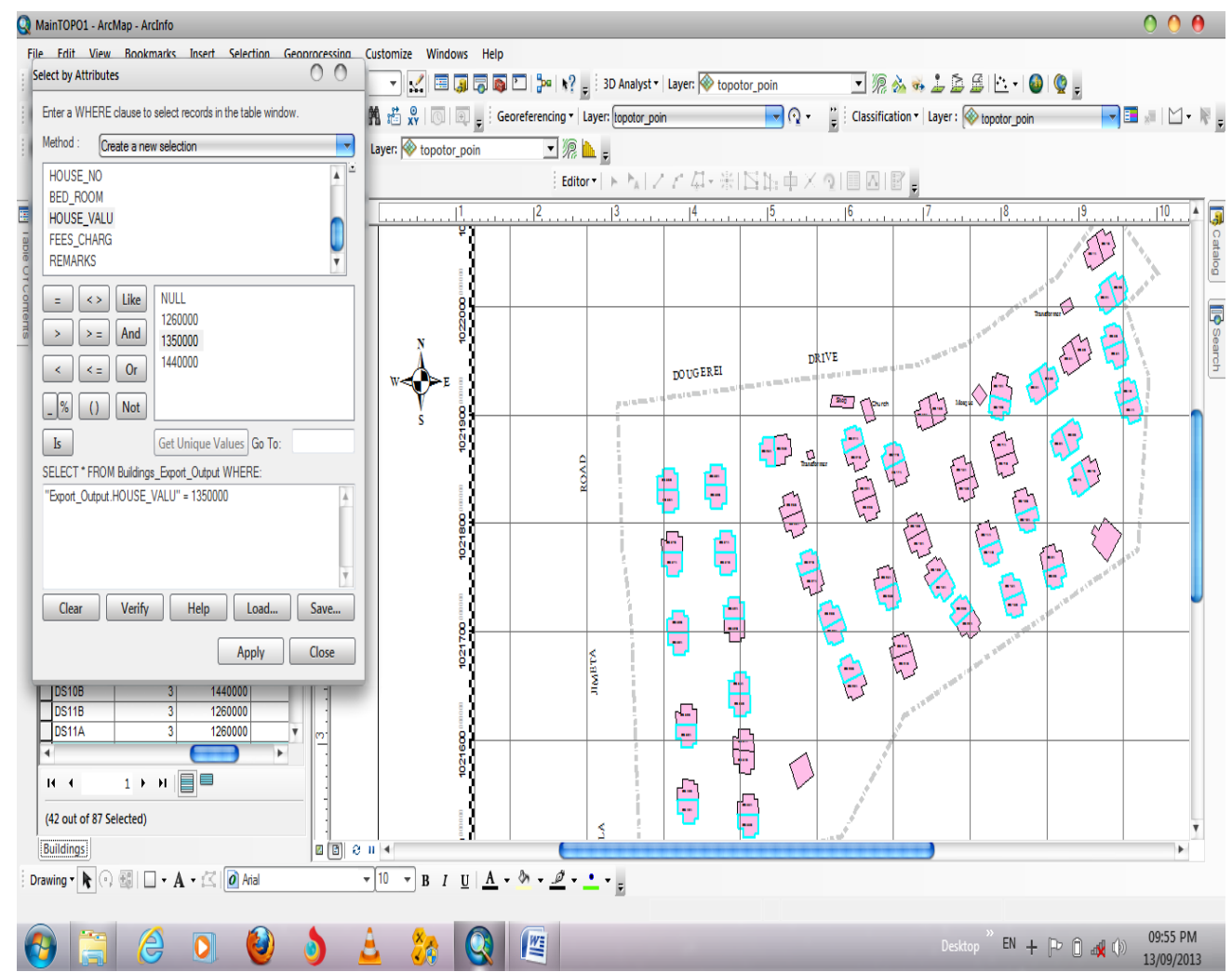

Figure 5: Query showing house value at $\$ 1,350,000.00$

\section{Summary And Conclusion}

In the process of production of the topographic map and the DTM, total station instrument and two software packages that include AutoCAD and ArcGIS were used for data acquisition, processing and presentation. These give more reliable information on the topographic configuration of the whole area. The design of the database, in which query were performed for residential house values was also carried out. These depicted the physical nature of the terrain showing places of low and high attitudes. It is evident, that the topographic map of the area can be employed for various engineering constructions and design. Such projects may include the construction of roads, buildings and water accessibility. It is also very important to mention here that eighty housing unit is a flood-prone area, and hence the topographic map can be efficiently employed in the construction of drainage channels and laying of pipelines be it water or telecommunication. Cost analyses are important aspects of flood vulnerability analysis and this study showed that the values of houses are not related to the low or high lands. Generally, houses to the east and south would be much affected due to their location in low land areas.

The production of the topographic map of the eighty housing units and the production of the digital terrain model (DTM) of the area could assist Town Planners, Engineers and Architects in the design and construction of houses, roads and drainage patterns that will control the effect of flooding. In addition, detailed topographic map can serve as base map for future planning and development. Additional analysis based on the DTM, such as viewshed and watershed analyses are recommended for investigations on flood in lowland areas. 


\section{References}

[1]. Agajelu, S.I. (1994). The prospect of establishing geographic data base management system in Nigeria. The map maker Vol. II.

[2]. Bannister, A. (2006). "Surveying" Dorling Kinderisly Publishing Inc. Delhi, India.

[3]. Bohler .W.Heinz. G.scherer.y.(1997). Using satellite images for Archaeological Docomentation. CIPA symposium Geoteborg. ISPRS proceedings. Vol xxxII,ww.

[4]. Diaz, J. H. Global climate change, natural disasters, and travel risks. J. of Travel Medicine, 2006, 13,361-372.

[5]. Ekpete, W. (2005), Geospatial data infrastructure, Concept cases and good practices, London UK.

[6]. Gottfried Konecny. (2003), geo-information, Remote sensing, photogrammetry and geographic information system published by Taylor francis $.11 \mathrm{nw}$ fether lane London.

[7]. Hill, D. R. (1996). A history of engineering in classical and Medieval Times. Springer Berlin.

[8]. Jonkman S. N. (2005), Global Perspectives on Loss of Human Life Caused by Floods. Natural Hazards, 34, 151-175.

[9]. Konecny, G. (2003), Geo-information, Remote Sensing, Photogrammetry and Geographic Information System. Taylor Francis, London.

[10]. Lowe, D. Kristi, L. E. and Forsberg, B. (2013). Review: Factors increasing vulnerability to health effects before, during and after floods. International Journal of Environmental Research and Public Health. Vol 10, 7015-7067.

[11]. NIMA (2004): Bulletin of the Nigerian Meteorological Authority. Abuja, Nigeria.

[12]. Owen, G. (2010): "remote sensing And Geographic information system". Publisher Mc Graw- Hill companies, inc. New York

[13]. Usa, A.A and Tukur, A.I. (2006): Applying remote sensing and GIS for the mapping of Basic Educational Schools in Adamawa State, Nigeria. 